\title{
Importance of genetic diversity in eelgrass Zostera marina for its resilience to global warming
}

\author{
Anneli Ehlers ${ }^{1,2, *}$, Boris Worm ${ }^{1,3}$, Thorsten B. H. Reusch ${ }^{2,4}$ \\ ${ }^{1}$ Leibniz Institute for Marine Sciences, IfM-Geomar, Düsternbrooker Weg 20, 24105 Kiel, Germany \\ ${ }^{2}$ Max-Planck-Institute for Limnology, August-Thienemann-Str. 2, 24306 Plön, Germany \\ ${ }^{3}$ Biology Department, Dalhousie University, Halifax, Nova Scotia B3H 4J1, Canada \\ ${ }^{4}$ Institute for Evolution and Biodiversity, University of Münster, Hüfferstr. 1, 48149 Münster, Germany
}

\begin{abstract}
Effects of global warming on marine ecosystems are far less understood than they are in terrestrial environments. Macrophyte-based coastal ecosystems are particularly vulnerable to global warming, because they often lack species redundancy. We tested whether summer heat waves have negative effects on an ecologically important ecosystem engineer, the eelgrass Zostera marina L., and whether high genotypic diversity may provide resilience in the face of climatic extremes. In a mesocosm experiment, we manipulated genotypic diversity of eelgrass patches fully crossed with water temperature (control vs. temperature stress) over $5 \mathrm{mo}$. We found a strong negative effect of warming and a positive effect of genotypic diversity on shoot densities of eelgrass. These results suggest that eelgrass meadows and associated ecosystem services will be negatively affected by predicted increases in summer temperature extremes. Genotypic diversity may provide critical response diversity for maintaining seagrass ecosystem functioning, and for adaptation to environmental change.
\end{abstract}

KEY WORDS: Climate change - Ocean warming • Coastal ecosystem $\cdot$ Genotypic diversity $\cdot$ Intraspecific variation $\cdot$ Resilience $\cdot$ Zostera marina

Resale or republication not permitted without written consent of the publisher

\section{INTRODUCTION}

Climate change affects the structure and functioning of many ecosystems (Gitay et al. 2002, Schroter et al. 2005). Coastal ecosystems are particularly vulnerable, because their resilience and capacity to buffer addi-

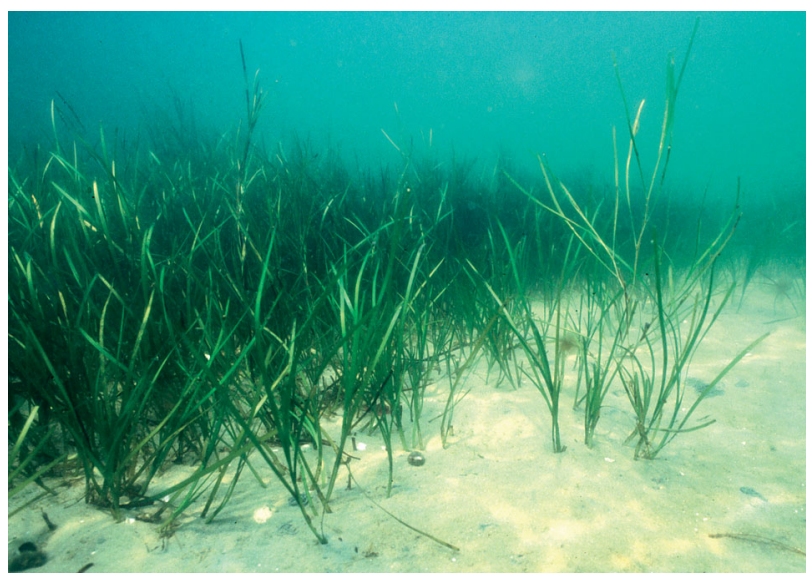

Edge of a dense, healthy eelgrass Zostera marina meadow in the western Baltic Sea.

Photo: T.B.H. Reusch

tional environmental stresses have already been undermined by human impacts such as overharvesting, pollution, eutrophication, and habitat destruction (Holling 1973, Hughes et al. 2003). Moreover, many disturbances are acting at the terrestrial-marine interface and are predicted to increase, such as increased land run-off after floods, higher wave energies (due to increased storm frequency) and increasing turbidity. The negative effects of ocean warming on coastal biota are already evident (Harley et al. 2006 and references therein).

Global and regional climate models not only forecast a rise in mean temperatures, but also an even stronger increase in frequency and intensity of extreme climatic events (IPCC 2007). Heat waves, such as the 2003 sum- 
mer heat wave in Europe, are likely to occur more frequently (Schär \& Jendritzky 2004, Beniston et al. 2007). Moreover, a regional climate model for the Baltic Sea area predicts an increase in mean summer temperatures of 3 to $5^{\circ} \mathrm{C}$ within the next century, which lies above the predicted global warming average (BACC 2006). In order to predict the fate of coastal communities and ecosystems, an assessment of the vulnerability of key coastal species to climate change is necessary (Short \& Neckles 1999, Harley et al. 2006). In the present study, we tested the effects of global warming on a Baltic population of the eelgrass Zostera marina L., a dominant coastal species that, as an ecosystem engineer (sensu Jones et al. 1994), contributes largely to habitat provision, nutrient cycling and primary productivity in temperate coastal ecosystems. Sustained water temperatures exceeding $25^{\circ} \mathrm{C}$ have been repeatedly reported to cause decline or die-off of eelgrass, both in the field and under experimental conditions (Short \& Neckles 1999 and references therein, Bintz et al. 2003). Most recently, die-back was observed for different seagrass species following the heat wave in summer 2003 (Mayot et al. 2005, Reusch et al. 2005).

In addition to the effects of temperature, we also tested for the effects of genotypic diversity of eelgrass on the performance of experimental communities. In marine ecosystems that are structured by foundation species such as seagrasses, kelps, mussels, oysters, or rockweeds, species diversity at the level of structuring species is low (Bruno et al. 2003, Micheli \& Halpern 2005). Recent evidence suggests that different functional traits displayed by distinct genotypes play an analogous role to species diversity in these environments, i.e. more genotypically diverse populations show enhanced resilience to different disturbances or settling success compared to less diverse communities (Hughes \& Stachowicz 2004, Gamfeldt et al. 2005, Reusch et al. 2005, Reusch \& Hughes 2006). Evidence for genetic or genotypic diversity buffering the negative effects of global warming is thus far only observational.

In the present study, we used temperature-controlled indoor mesocosms to test the hypothesis that a simulated summer heat wave has a negative effect on eelgrass performance. In a factorial design, we also manipulated the genotypic diversity of eelgrass to test its ability to buffer losses caused by warming.

\section{MATERIALS AND METHODS}

Study species. Our study organism, the eelgrass Zostera marina L., is distributed worldwide in northern temperate coastal zones, where it forms extensive meadows that stabilize coastal sediments and provide the basis of diverse food webs (Williams \& Heck 2001,
Duffy 2006). The clonal growth of $Z$. marina allows replicated shoots (ramets) of the same genotype to be isolated. Therefore, as proven by previous studies in this system (Williams 2001, Hughes \& Stachowicz 2004, Reusch et al. 2005, Ransbotyn \& Reusch 2006), $Z$. marina is a suitable organism to test for the importance of genotypic diversity, and is expected to continue to be used in future research (Duffy 2006, Reusch \& Hughes 2006, Procaccini et al. 2007).

Donor site and clonal mapping. The Zostera marina plants used for this study were obtained from dense perennial eelgrass beds in Maasholm, Schlei $\left(54^{\circ} 41^{\prime} \mathrm{N}, 10^{\circ} 00^{\prime} \mathrm{E}\right)$, a shallow estuary on the German Baltic coast. Beds grow at a depth of 1.6 to $1.8 \mathrm{~m}$ and are composed of clones that range from 0.1 to $10 \mathrm{~m}^{2}$ in size (Hämmerli \& Reusch 2003). Eelgrass was sampled in April 2004 at $33.3 \mathrm{~cm}$ intervals based on a $10 \times 10 \mathrm{~m}$ grid within a closed eelgrass meadow using SCUBA. Leaf tissue (1 cm length) was taken from the shoot nearest to every grid point, resulting in 900 individual samples. Leaf samples were dried and stored in individual tubes on silica gel. DNA was extracted using Qiagen DNeasy Plant Kit. A multiplex PCR amplification using 4 microsatellite markers (GenBank Acession Nos.: AJ249307, AJ249305, AJ009900, AJ009898) was carried out in accordance with published protocols (Reusch 2002, Hämmerli \& Reusch 2003, Reusch et al. 2005). Samples ran on an ABI 3100 capillary sequencer and alleles were scored using GenScan Analysis 3.1 and Genotyper 2.0 Software (Applied Biosystems 2001). Based on the resulting clone map, 12 eelgrass clones with sufficient numbers of shoots (ramets) were targeted for sampling in June 2004, 6 of which covered an area of $>2 \mathrm{~m}^{2}$.

Experimental design. The experiment was conducted in an indoor mesocosm facility at the Leibniz Institute for Marine Sciences in Kiel, Germany. It was set up as a randomised block design in 12 tanks (blocks) containing 4 sub-containers each. Every container (= plot) was planted with 18 eelgrass ramets (independent shoot units = one main shoot attached to an 8 to $10 \mathrm{~cm}$ rhizome). The experiment was a $2 \times 3$ factorial design with warming (heated/ambient) and genotypic diversity of eelgrass $(1,3,6$ genotypes) as independent variables (Fig. 1). Six tanks were heated (see below); the other 6 were held at ambient temperature. Each tank was considered as 1 block and contained 4 plots, of which 2 were 1-genotype treatments (monocultures), 1 was a 3-genotype treatment and 1 was a 6-genotype treatment, randomly assigned to a position within the block. For each warming level, we had 2 replicates of 1 -genotype treatments of 6 clones $(\mathrm{n}=24)$ and 6 replicates each of 3- and 6-genotype treatments $(\mathrm{n}=12)$. 
Within the highest diversity level, half of the 6-genotype treatments were composed of the 6 genotypes used for 1- and 3-genotype plots (see Fig. 1; $6_{(6)}$ ); another 6 treatments were composed of a random assortment of 6 genotypes drawn from a total of 12 genotypes $\left(6_{(12)}\right)$. This was done to assure compositional replication at the highest diversity level, as former diversity experiments were criticised for the fact that higher diversity plots were more similar to one another in composition than lower diversity plots (Fukami et al. 2001).

The experimental mesocosm tanks had a volume of 6001 each and contained ambient Baltic Sea water with a flow rate of $100 \mathrm{l} \mathrm{h}^{-1}$ per tank. Additionally, the water within the tanks was circulated by air bubbles released by a perforated hose at the bottom of each tank, to prevent microalgal blooms at the water surface. Individual plots consisted of four $48 \times 41 \times 16 \mathrm{~cm}$ polyethylene compartments embedded within each tank. These compartments were filled with sandy sediment to a height of $12 \mathrm{~cm}$. Each tank was equipped with a light panel $(2 \times 150 \mathrm{~W}$, HQI-lamp), $50 \mathrm{~cm}$ above the water surface with a diurnal rhythm of $15: 9 \mathrm{~h}$ light:dark, according to the high latitudinal light regime during summer months. Average light levels were $144 \mu \mathrm{mol} \mathrm{m} \mathrm{m}^{-2} \mathrm{~s}^{-1}$ (just below water surface) and $65 \mu \mathrm{mol} \mathrm{m}{ }^{-2} \mathrm{~s}^{-1}$ (20 $\mathrm{cm}$ below surface).

Sediment was taken from a nearby shoreline and enriched with sediment from the donor seagrass bed, to provide original microfaunal and microbial compo-
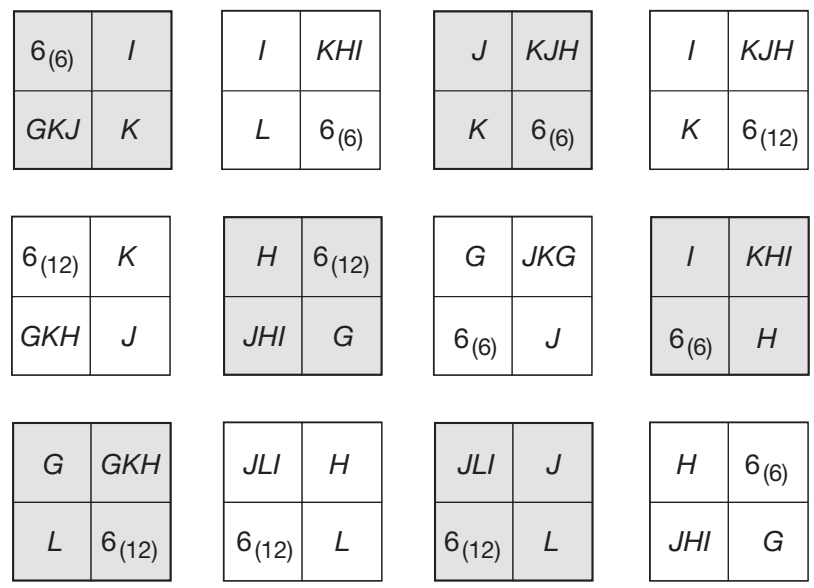

Fig. 1. Experimental set-up of the indoor mesocosm facility at IfM-GEOMAR, Kiel, Germany, comprising 12 blocks (= tanks of $600 \mathrm{l}$ ) containing 4 plots each. Grey shading represents warmed tanks. Eelgrass Genotypes $G-L$ were planted in monoculture; 3 - and 6-genotype mixtures are indicated by letters or letter combinations. $6_{(6)}$ : plots with a 6-genotype mixture containing ramets from all 6 Genotypes $G-L_{i} 6_{(12)}$ : plots randomly composed out of a wider pool of 12 genotypes, containing Genotypes $G-L$ and 6 others that were not cultured as monocultures nents as an inoculum. To control the growth of epiphytic algae we added 250 individuals of the grazing snail Littorina littorea L. to each tank. Isopods Idothea baltica L. (12 ind. per tank) were added as alternative grazers. In addition, natural settlement and growth of larvae from Kiel fjord was allowed, resulting in recruitment of mostly mussels (Mytilus edulis, Mya arenaria) and polychaetes (Nereidae, Pygospionidae) within our mesocosms.

The experiment was set up in mid-June 2004. After an initial $6 \mathrm{wk}$ of acclimatisation, the water temperature in half of the tanks was raised to $25^{\circ} \mathrm{C}$, which replicated the conditions observed in 2003 (Reusch et al. 2005), when a heat wave caused increased warming across northern Europe (Schär \& Jendritzky 2004). Stainless steel heating rods $(5 \times 300 \mathrm{~W}$ per tank), placed into the water columns and maintained for $4 \mathrm{wk}$ (4 August to 1 September 2004), were used for the warming treatment. The remaining 6 tanks were held at ambient water temperature of Kiel Fjord (see 'Results'; Fig. 2). After the heating period, eelgrass in the experiment was allowed to develop under ambient flow-through conditions for $6 \mathrm{wk}$, until the shoots were destructively harvested from 10 to 15 October 2004.

Response variables. Water temperatures were recorded daily during the heating period. In October, the eelgrass was destructively harvested, allowing shoots per treatment to be counted and main shoots and newly developed lateral shoots to be distinguished; plant biomass was separated into above- and belowground parts. Epiphytes were wiped off the shoots, and rhizomes were cleaned from adherent sediment particles before being dried for $>24 \mathrm{~h}$ at $60^{\circ} \mathrm{C}$ and weighed to the closest $0.1 \mathrm{mg}$. Biomasses were then

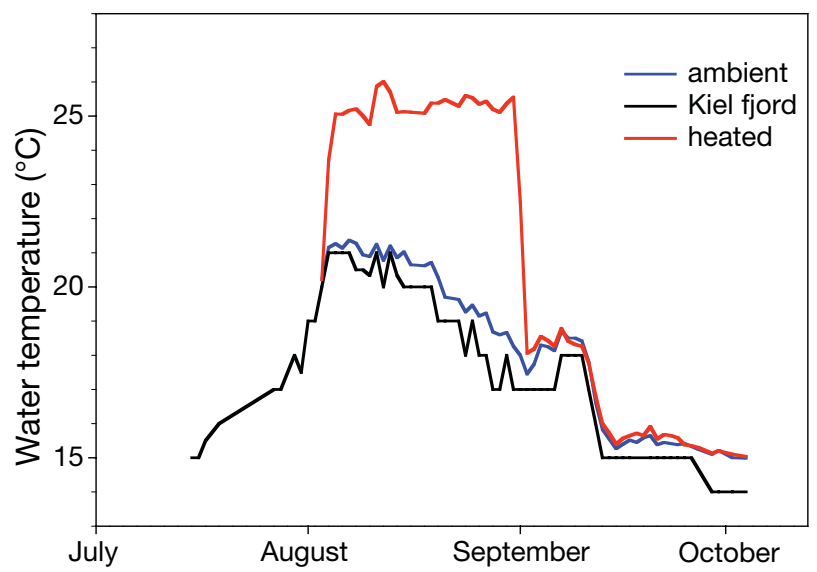

Fig. 2. Water temperatures during the experimental period in summer 2004. The background temperature from Kiel fjord was measured at a depth of $6 \mathrm{~m}$; daily mean temperatures of ambient and heated treatments are shown as blue and red lines 
summed up per genotype per treatment. We made 2 additional shoot counts during the experiment, one before (July) and one after (September) experimental warming. For the analyses, shoot numbers were from pooled main and lateral shoots. Epiphyte cover, grazer counts and distribution records were taken on 1 September 2004.

Data analysis. The experiment was laid out as a factorial split plot design. For the main analysis we used a generalized linear mixed effects model (GLMM); 'genotypic diversity' was considered a continuous and 'warming' a categorical fixed factor, whereas 'block' was treated as a random factor, which was nested within the 'warming' treatment. The response variables were shoot density per plot from shoot counts in July, September and October. In addition, we analysed eelgrass biomass in October. When necessary, data were transformed $\left(\log _{10}\right)$ to meet model assumptions. Where this was not possible, we used a non-parametric test (e.g. for epiphyte cover). All analyses were conducted using the General Linear Model platform within STATISTICA for Windows v. 6.1 software (StatSoft, www.statsoft.com).

\section{RESULTS}

The warming treatment was maintained at a mean water temperature $( \pm \mathrm{SE})$ of $25.3 \pm 0.1^{\circ} \mathrm{C}$ during the experimental warming period (Fig. 2). This was on average $5.0 \pm 0.2^{\circ} \mathrm{C}$ above the ambient temperature in the control tanks. The timing of the warming treatment corresponded to the warmest summer temperatures measured in Kiel Fjord in 2004 (Fig. 2) and closely simulated observed field conditions during the 2003 heat wave.
Warming had a negative effect on eelgrass shoot density. In July, 1 mo after planting and prior to warming, shoot numbers were not statistically different between warmed and ambient tanks (Fig. 3A). Six weeks later, directly after termination of the heat treatment (2 September 2004), a negative effect of warming on shoot density was apparent but not statistically significant ( $p=0.05029$ ). In the following $6 \mathrm{wk}$ up to the final sampling in October, we observed increased detachment of shoots in all tanks, unrelated to former warming treatment ( $t$-test, counts of drifting shoots on surface of tanks, $\mathrm{p}=0.24$ ). However, final shoot count in October showed on average $44 \%$ fewer shoots in warmed treatments compared to treatments which had experienced ambient water temperatures $(\mathrm{p}=0.029$; see Table 1, Fig. 3C). Plants in ambient water tanks had developed more lateral shoots compared to formerly warmed treatments, where mainly terminal shoots had been maintained (GLM, heat; $F_{1,34}=4.29$; $\mathrm{p}=0.048)$.

The positive effect of eelgrass genotypic diversity developed over the experimental period (Table 1). In July, we found a tendency towards a positive effect of increased genotypic diversity on eelgrass shoot density ( $p=0.056)$. In September, there was a significant positive effect of genotypic diversity on shoot numbers $(\mathrm{p}=$ 0.021). Six weeks later in October this effect became even more apparent $(p=0.014)$. A positive diversity effect was also observed between the 2 variants of plots of highest diversity in July. Those 6-genotype mixtures assembled from a pool of 12 genotypes $\left(6_{(12)}\right)$ had developed more shoots than those composed out of a pool of 6 genotypes $\left(6_{(6)}\right)(t$-test, $p=0.006)$. During September and October, the differences in shoot densities between the 2 variants of high-diversity treatments disappeared ( $t$-test, $\mathrm{p}>0.5$ ). For all censuses of
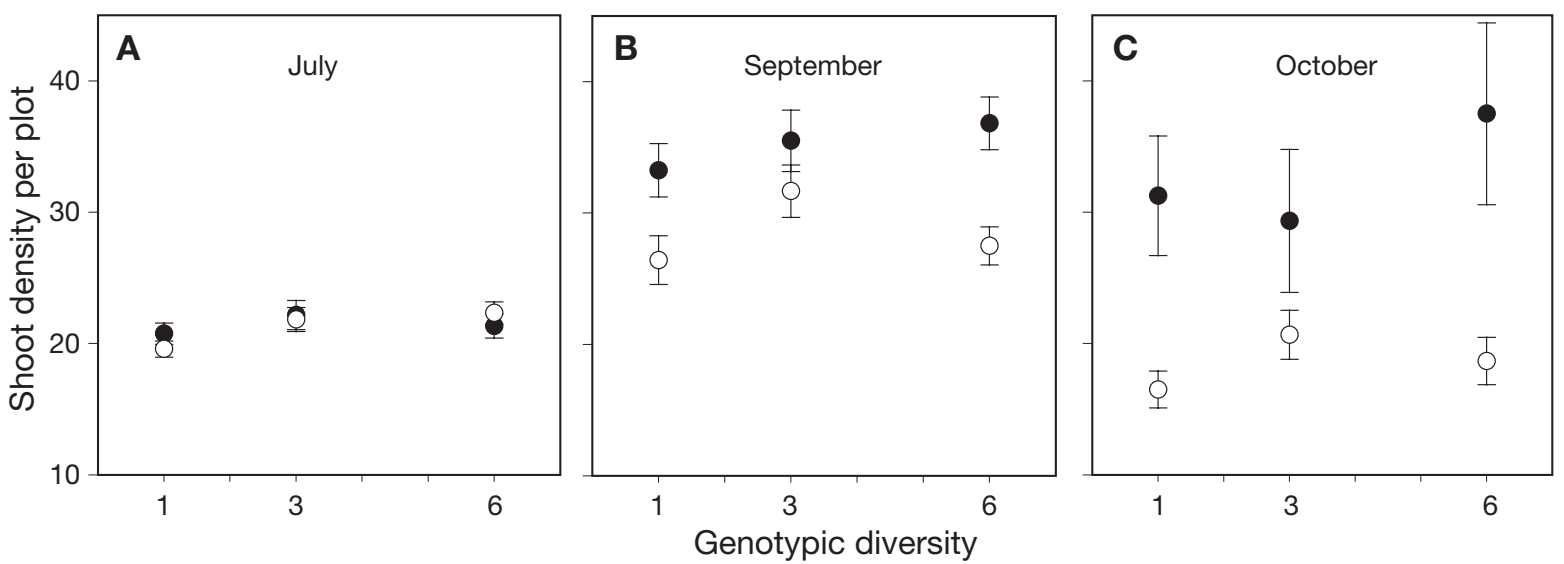

Fig. 3. Zostera marina. Response of the eelgrass to warming: shoot numbers (mean \pm SE) for ambient $(\bullet)$ and warmed $(0)$ experimental mesocosms for the 3 genotypic diversity levels (1-, 3- and 6-genotypes) in (A) July (before heat treatment), (B) September (termination of heat treatment) and (C) October 2004 (6 wk after heat treatment). Sample sizes are $\mathrm{n}=24$ for 1 -genotype treatments, and $n=12$ for others 
Table 1. General linear mixed effects model (GLMM) of the effects of experimental warming and genotypic diversity on eelgrass shoot density. 'Genotypic diversity' was treated as a continuous, and 'warming' as a categorical fixed factor, while 'block' was treated as a random factor. Diversity or Div: genotypic diversity; Warming or W: experimental warming; Block (W): block was nested within the warming treatment

\begin{tabular}{|c|c|c|c|c|c|c|c|c|}
\hline \multirow[t]{2}{*}{ Source } & \multirow[t]{2}{*}{ df } & \multicolumn{2}{|c|}{ July } & \multicolumn{2}{|c|}{ September } & \multicolumn{2}{|c|}{ October } & \multirow[t]{2}{*}{ Denominator } \\
\hline & & $F$ & $\mathrm{p}$ & $F$ & $\mathrm{p}$ & $F$ & $\mathrm{p}$ & \\
\hline Warming & 1 & 1.65 & 0.227 & 4.95 & 0.050 & 6.49 & 0.029 & Block (W) \\
\hline Block (W) & 10 & 1.34 & 0.267 & 0.68 & 0.729 & 1.48 & 0.206 & Residual \\
\hline Diversity & 1 & 4.68 & 0.056 & 7.41 & 0.021 & 8.79 & 0.014 & Block $(\mathrm{W}) \times$ Div \\
\hline Warming $\times$ Div & 1 & 1.63 & 0.230 & 0.38 & 0.550 & 0.24 & 0.635 & Block $(\mathrm{W}) \times$ Div \\
\hline Block $(\mathrm{W}) \times$ Div & 10 & 1.17 & 0.355 & 0.21 & 0.993 & 0.28 & 0.979 & Residual \\
\hline Residual & 24 & & & & & & & \\
\hline
\end{tabular}

shoot numbers we found no interaction for 'warming' and 'genotypic diversity' (Table 1; all p > 0.2). Further, we found neither temperature nor diversity effects on eelgrass above- or belowground biomass (data not shown; $\mathrm{p}>0.1$ ).

The analysis of the performance of individual genotypes suffers from limited power due to the small sample size $(n=2)$ for each genotype in monoculture under both temperature conditions. Nevertheless, there is some statistical support for differential performance among clones. Individual genotypes yielded significantly different shoot numbers in July, prior to experimental warming (1-way ANOVA, $\left.F_{5,18}=5.18 ; \mathrm{p}=0.004\right)$. Post-hoc comparisons between genotypes showed that this difference was due to Genotype $I$ ( $\mathrm{p}<0.05$; see Fig. 4), which generally performed best. In September and October, no significant differences between shoot numbers of individual monocultures and their reaction to warming were detectable (Fig. 4). In ambient treatments, all 6 genotypes increased their shoot densities until September, when 4 of them began to loose shoots. Genotype $I$ showed a nearly linear increase of shoots until harvest in October. In the warmed plots, monocultures composed of the Genotypes $H, L$ and $K$ ) were strongly affected by raised temperatures and were not able to produce numerous new shoots. The other 3 genotypes $(G, I, J)$ reached shoot densities similar to those in ambient tanks in September. At the point of harvest in October, shoot density in warmed treatments in all but one genotype (I) had declined below initial densities (Fig. 4).

Cyanobacterial mats probably influenced light and nutrient conditions, and thus seagrass productivity in the mesocosms. Estimations of cover per tank at the end of the heating period (1 September 2004) revealed that on average $3 \%$ of ambient treatments were covered by biofilm-forming cyanobacteria, coating sediment surface or plants, compared to $28 \%$ cover in the warmed plots (Mann-Whitney $U$-test; $U=5.5 ; \mathrm{p}=$ 0.041). We also found an effect of warming on the distribution of the main grazer Littorina littorea. In heated tanks, $16 \%$ of snails attached themselves to the inner tank wall above the water surface compared to $7 \%$ in the ambient tanks (1-way ANOVA; $F_{1,10}=20.6 ; \mathrm{p}=$
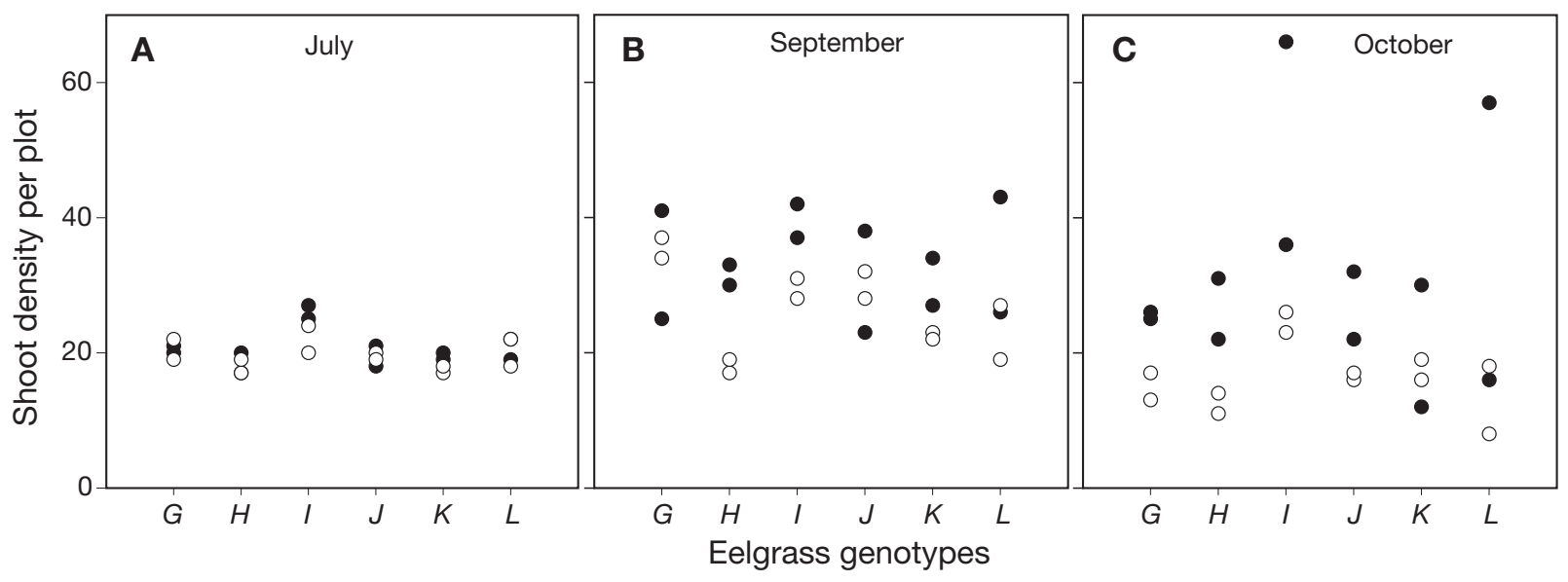

Fig. 4. Zostera marina genotypes and their responses to experimental warming. Shoot numbers in replicates of 6 eelgrass clones $(G-L)$ are shown for ambient $(\bullet)$ and warmed (O) experimental mesocosms in (A) July (before heat treatment), (B) September (termination of heat treatment) and (C) October 2004 (6 wk after heat treatment) 
0.001). Despite their altered behaviour, the final abundance of snails in October was not affected by warming (1-way ANOVA; $\mathrm{p}>0.5)$. In all tanks, additional snails had recruited over the experimental period.

\section{DISCUSSION}

Although there is a growing body of literature on coastal ecosystems and the possible effects of climate change (Short \& Neckles 1999, Duarte 2002, Gitay et al. 2002, Hughes et al. 2003, Oviatt 2004, Harley et al. 2006), few experiments simulated realistic increases in water temperature in coastal communities (but see Williams 2001, Bintz et al. 2003, Allison 2004). To our knowledge, our experimental study is the first that directly manipulated water temperatures as a component of global change combined with different genotypic diversities in any plant community. Our experiment demonstrated a negative effect of temperature conditions, simulating the 2003 summer heat wave in Europe, on a temperate population of eelgrass Zostera marina. The percentage loss of shoot numbers in our warmed tanks relative to the control tanks (44\%) approached the magnitude of shoot loss observed in the field during the 2003 heat wave, compared to former years (48 to $52 \%$; Reusch et al. 2005). Furthermore, we observed a positive effect of high genotypic diversity on eelgrass shoot densities. This outcome was less pronounced in our experiment, compared with effects observed in the field in 2003 (Reusch et al. 2005).

The negative effect of the prolonged water temperature maxima on shoot densities increased over time (see Table 1, Fig. 3). The difference in final shoot densities between ambient and warmed treatments was due to a shift in the growth strategy of eelgrass under warmed conditions. Ramets in warmed treatments showed less vegetative recruitment (as new lateral shoots) in October than those in ambient treatments. This observation is in accordance with previous studies where eelgrass in combination with other macrophytes was exposed to increased water temperatures (Bintz et al. 2003).

Considering the heat waves that have already occurred in Europe, and a predicted increase in such events (Beniston et al. 2007), our temperature treatment of $25^{\circ} \mathrm{C}$ water temperature for 4 wk represents a highly probable scenario. Continuously high temperatures during the day and night reduce the internal oxygen concentration in eelgrass to critically low levels, especially during the night (Borum et al. 2006).

Increased genotypic diversity had a positive effect on shoot density after termination of the warming treatment in September and October. The mechanisms underlying these patterns are unclear. We suggest a selection effect, as the average performance of Genotype $I$, which also performed well in monoculture, was better than that of all other genotypes. Another possibility would be facilitation, for example, acting via complementarity of resource use. It is further unknown whether positive diversity effects will also appear after the establishment of a permanent stressor or multiple stressors acting synergistically on an eelgrass system.

Taken together, field observations and mesocosm results jointly support the hypothesis that genotypic diversity is important in providing different responses to environmental variation (Whitham et al. 2003, Gamfeldt et al. 2005, Hughes et al. 2005). Although we found statistical support for among-genotype differentiation in shoot density only in July, field data from 2003 showed highly differentiated responses of individual eelgrass genotypes to prolonged summer temperature maxima (Reusch et al. 2005). This genetic variation may be critical in maintaining the resilience of ecosystems that are based on single habitat-forming species (Duffy 2006, Reusch \& Hughes 2006) and may provide the potential for selection towards heat-tolerant genotypes and hence adaptation to changing environmental conditions.

Without doubt, our planted mesocosm 'community' did not capture the full complexity of natural seagrass communities. For example, other grazer species such as isopods and amphipods were underrepresented in our experiment and may react differently to ocean warming than littorinid snails. The observed appearance of cyanobacterial mats and the reduced grazing activity of gastropods may be an artefact of our mesocosms. Therefore, we cannot completely exclude the possibility that the negative response of shoot density to the warming treatment was produced by indirect processes that exacerbated direct temperature effects. Nevertheless, the magnitude of negative temperature effects observed here was nearly identical to field observations (Reusch et al. 2005). Moreover, our findings are in line with studies and observations on other seagrass species (Koch \& Erskine 2001, Mayot et al. 2005).

Losses of seagrass over the last decades are dramatic and may accelerate with increasing climate change (Short \& Neckles 1999 and references therein; Oviatt 2004). As seagrass meadows represent important habitats on marine soft-bottom sediments in higher latitudes, regional decline or extinction of this species could lead to regime shifts in coastal areas, with unpredictable ecosystem effects (Harley et al. 2006).

Our results present a stark warning that eelgrass meadows and their associated ecosystems may not be able to keep pace with rapid global warming. In the present study, we found that genotypic diversity 
enhanced resistance to temperature stress. Therefore, it is wise to protect seagrass bed genetic diversity in order to maximize the capacity of meadows to resist disturbances associated with global change. This applies particularly to beds that are being restored by habitat mitigation (Williams 2001). The potential for seagrass beds to undergo rapid evolutionary adaptation as a response to warming stress as a function of genetic variation in critical traits associated with stress tolerance still is largely unexplored. Thus, the conservation of genetic and genotypic diversity may be crucial for evolutionary adaptation of eelgrass systems to global climate change (Reusch \& Wood 2007).

Acknowledgements. We thank W. Lampert and U. Sommer for encouragement and support; S. Carstensen, I. Dankert, A. Duse, T. Hansen, N. Langhanki and P. Schwab for technical or field assistance; $\mathrm{H}$. Lotze and 4 anonymous reviewers for helpful comments; and the IfM-Geomar for logistical support. The authors were supported by the Deutsche Forschungsgemeinschaft (A.E. and B.W.: DFG Wo 818/1-2; T.B.H.R.: DFG Re1108/4 and 6).

\section{LITERATURE CITED}

Allison G (2004) The influence of species diversity and stress intensity on community resistance and resilience. Ecol Monogr 74:117-134

Applied Biosystems (2001) GenScan Analysis Software (3.1) and Genotyper Software (2.0). Applied Biosystems, Foster City, CA

BACC Lead Author Group (2006) Assessment of Climate Change for the Baltic Sea Basin-The BACC Project, International BALTEX Secretariat Publication No. 35. GKSS, Geesthacht

Beniston M, Stephenson DB, Christensen OB, Ferro CAT and others (2007) Future extreme events in European climate: an exploration of regional climate model projections. Clim Change 81:71-95

Bintz JC, Nixon SW, Buckley BA, Granger SL (2003) Impacts of temperature and nutrients on coastal lagoon plant communities. Estuaries 26:765-776

Borum J, Sand-Jensen K, Binzer T, Pedersen O, Greve TM (2006) Oxygen movement in seagrasses. In: Larkum AWD, Orth RJ, Duarte CM (eds) Seagrasses: biology, ecology and conservation. Springer, Dordrecht, p 255-270

Bruno JF, Stachowicz JJ, Bertness MD (2003) Inclusion of facilitation into ecological theory. Trends Ecol Evol 18:119-125

Duarte CM (2002) The future of seagrass meadows. Environ Conserv 29:192-206

Duffy JE (2006) Biodiversity and the functioning of seagrass ecosystems. Mar Ecol Prog Ser 311:233-250

Fukami T, Naeem S, Wardle DA (2001) On similarity among local communities in biodiversity experiments. Oikos 95: 340-348

Gamfeldt L, Wallén J, Jonsson PR, Berntsson KM, Havenhand JN (2005) Increasing intraspecific diversity enhances settling success in a marine invertebrate. Ecology 86: 3219-3224

Gitay H, Suárez A, Watson RT Dokken DJ (eds) (2002) Climate change and biodiversity. Intergovernmental Panel on Climate Change, Geneva

Hämmerli A, Reusch TBH (2003) Inbreeding depression in- fluences genet size distribution in a marine angiosperm. Mol Ecol Notes 12:619-629

Harley CDG, Hughes AR, Hultgren KM, Miner BG and others (2006) The impacts of climate change in coastal marine systems. Ecol Lett 9:228-241

Holling CS (1973) Resilience and stability of ecological systems. Annu Rev Ecol Syst 4:1-23

Hughes AR, Stachowicz JJ (2004) Genetic diversity enhances the resistance of a seagrass ecosystem to disturbance. Proc Natl Acad Sci USA 101:8998-9002

- Hughes TP, Baird AH, Bellwood DR, Card M and others (2003) Climate change, human impacts, and the resilience of coral reefs. Science 301:929-933

Hughes TP, Bellwood DR, Folke C, Stenek RS, Wilson J (2005) New paradigms for supporting the resilience of marine ecosystems. Trends Ecol Evol 20:380-386

IPCC (Intergovernmental Panel on Climate Change) (2007) Climate change 2007: impacts, adaptation and vulnerability. Fourth Assessment Report-Summary for Policymakers. WG II, IPCC, Geneva, p 1-23

Jones CG, Lawton JH, Shachak M (1994) Organisms as ecosystem engineers. Oikos 69:373-386

Koch MS, Erskine JM (2001) Sulfide as a phytotoxin to the tropical seagrass Thalassia testudinum: interactions with light, salinity and temperature. J Exp Mar Biol Ecol 266:81-95

Mayot N, Boudouresque CF, Leriche A (2005) Unexpected response of the seagrass Posidonia oceanica to a warmwater episode in the North Western Mediterranean Sea. C R Biol 328:291-296

Micheli F, Halpern BS (2005) Low functional redundancy in coastal marine assemblages. Ecol Lett 8:391-400

Oviatt CA (2004) The changing ecology of temperate coastal waters during a warming trend. Estuaries 27:895-904

Procaccini G, Olsen JL, Reusch TBH (2007) Contribution of genetics and genomics to seagrass biology and conservation. J Exp Mar Biol Ecol 350:234-259

Ransbotyn V, Reusch TBH (2006) Housekeeping gene selection for quantitative real-time PCR assays in the seagrass Zostera marina subjected to heat stress. Limnol Oceanogr Methods 4:367-373

Reusch TBH (2002) Microsatellites reveal high population connectivity in eelgrass (Zostera marina) in two contrasting coastal areas. Limnol Oceanogr 47:78-85

Reusch TBH, Hughes AR (2006) The emerging role of genetic diversity for ecosystem functioning: estuarine macrophytes as models. Estuar Coast 29:170-175

Reusch TBH, Wood T (2007) Molecular ecology of global climate change. Mol Ecol 16:3973-3992

Reusch TBH, Ehlers A, Hämmerli A, Worm B (2005) Ecosystem recovery after climatic extremes enhanced by genotypic diversity. Proc Natl Acad Sci USA 102:2826-2831

> Schär C, Jendritzky G (2004) Hot news from summer 2003. Nature 432:559-560

> Schroter D, Cramer W, Leemans R, Prentice IC and others (2005) Ecosystem service supply and vulnerability to global change in Europe. Science 310:1333-1337

Short FT, Neckles HA (1999) The effects of global climate change on seagrasses. Aquat Bot 63:169-196

> Whitham TG, Young WP, Martinsen GD, Gehring CA and others (2003) Community and ecosystem genetics: a consequence of the extended phenotype. Ecology 84:559-573

Williams SL (2001) Reduced genetic diversity in eelgrass transplantations affects both population growth and individual fitness. Ecol Appl 11:1472-1488

Williams SL, Heck KL (2001) Seagrass community ecology. In: Bertness MD, Gaines SD, Hay ME (eds) Marine community ecology. Sinauer Associates, Sunderland, MA, p 317-337 